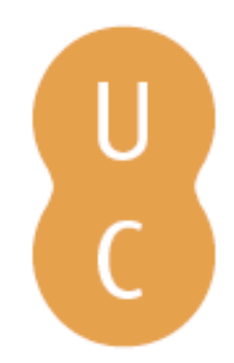

\title{
pommalina
}

\section{A edição quinhentista do comentário barbosiano à História Apostólica de Arátor}

\author{
Autor(es): $\quad$ Manso, José Henrique Rodrigues
}

Publicado por: Imprensa da Universidade de Coimbra; Sapienza. Universitá di Roma

URL

persistente: $\quad$ URI:http://hdl.handle.net/10316.2/38773

DOI: $\quad$ DOI:http://dx.doi.org/10.14195/978-989-721-044-0_6

Accessed : $\quad$ 26-Apr-2023 15:46:41

A navegação consulta e descarregamento dos títulos inseridos nas Bibliotecas Digitais UC Digitalis, UC Pombalina e UC Impactum, pressupõem a aceitação plena e sem reservas dos Termos e Condições de Uso destas Bibliotecas Digitais, disponíveis em https://digitalis.uc.pt/pt-pt/termos.

Conforme exposto nos referidos Termos e Condições de Uso, o descarregamento de títulos de acesso restrito requer uma licença válida de autorização devendo o utilizador aceder ao(s) documento(s) a partir de um endereço de IP da instituição detentora da supramencionada licença.

Ao utilizador é apenas permitido o descarregamento para uso pessoal, pelo que o emprego do(s) título(s) descarregado(s) para outro fim, designadamente comercial, carece de autorização do respetivo autor ou editor da obra.

Na medida em que todas as obras da UC Digitalis se encontram protegidas pelo Código do Direito de Autor e Direitos Conexos e demais legislação aplicável, toda a cópia, parcial ou total, deste documento, nos casos em que é legalmente admitida, deverá conter ou fazer-se acompanhar por este aviso. 


\section{Aires Barbosa na}

\section{Cosmopólis Renascentista}

Italo Pantani, Margarida Miranda \& Henrique Manso (coordenadores)

IMPRENSA DA UNIVERSIDADE DE COIMBRA

SAPIENZA. UNIVERSITÁ DI ROMA 


\title{
A EDIÇÃo QUINHENTISTA DO COMENTÁRIO BARBOSIANO À Historla Apostolica de Arátor
}

\author{
José Henrique Rodrigues Manso \\ Universidade da Beira Interior
}

Este artigo é baseado na comunicação que proferimos aquando do colóquio Aires Barbosa na Cosmópolis Renascentista, realizado em 15 de novembro de 2011 em Coimbra, cidade onde, há 476 anos, Aires Barbosa editou a sua última obra, a Antimoria. Gostaríamos, pois, de agradecer, desde já, aos três centros ( $\mathrm{CECH}, \mathrm{CEC}$ e APENEL) que uniram esforços para realizar esta iniciativa sobre um autor a quem temos dedicado muito do nosso tempo e estudo. $\mathrm{O}$ presente artigo foca a obra-prima do humanista aveirense, o Comentário à "Historia apostolica" de Arátor, no que concerne a aspetos editoriais, que não podem ser dissociados dos avanços e contingências da imprensa nos inícios de Quinhentos.

Comecemos por traçar uma brevíssima biografia de Aires Barbosa. Sobrinho do humanista Martim de Figueiredo, Barbosa nasceu por volta de 1470 em Esgueira, e foi em solo luso que fez as primeiras letras. Embora a crítica seja unânime em afirmar que, por volta de 1482, Barbosa rumou a Salamanca, onde hauriu o saber de grandes mestres como António de Nebrija ou Lúcio Marineo Sículo, nenhum texto ou documento confirma a sua presença na cidade do Tormes antes de 1495. Sabemos, no entanto, que, por volta de 1490, seguiu para Florença, tendo sido aluno de Ângelo Policiano, o mestre de quem se dirá orgulhosamente discípulo ao longo de toda a vida, e convivido com personalidades de renome, como João de Médicis, Hermolao Barbaro ou Pico della Mirandola. Em 1495, é convidado a integrar o corpo docente da Universidade de Salamanca, e a cátedra de Grego arranca nesse ano com Aires Barbosa. Foi ele o primeiro a ensinar a língua helénica a nível universitário em toda a Península Ibérica, o que lhe valeu o honroso epíteto de Mestre Grego. Em 1503, Aires Barbosa acrescentou ao Grego a Retórica, que abandonaria quando, em 1509, conseguiu a almejada cátedra de Gramática, mais prestigiada e com um salário muito superior. Jubilandose em 1523, Barbosa regressou a Portugal, onde, a pedido de D. João III, se torna mestre do infante cardeal D. Afonso. Faleceu na sua terra natal, Esgueira, a 20 de janeiro de $1540^{1}$.

\footnotetext{
${ }^{1}$ Sobre a vida de Aires Barbosa, vejam-se, entre outros, Francisco Ferreira Neves, «Vida e testamento de Aires Barbosa», Arquivo do distrito de Aveiro, 14 (Aveiro, 1948), p. 42-64; e José Henrique Manso, Comentário de Aires Barbosa ao segundo livro da Historia apostolica de Arátor, Lisboa, FCG/FCT, 2011, p. 28-42.
} 
Centremo-nos agora na obra que o humanista editou em Salamanca no ano de 1516 para inferirmos, a partir da análise dos originais, aspetos importantes da tipografia salmantina de então. No âmbito da regência do Latim (Retórica e Gramática), entre 1511 e 1517, Barbosa publicou na cidade do Tormes obras de caráter didático, destinadas a esclarecer os seus discípulos acerca das matérias lecionadas, sobretudo de índole gramatical: quatro opúsculos, um sobre verbos impessoais, outro sobre métrica latina, um terceiro sobre ortografia e, finalmente, um trabalho sobre prosódia. A estes junta-se o extenso Comentário à "Historia apostolica" de Arátor (1516), com cerca de centena e meia de fólios, a obra-prima do humanista e que constitui por si só mais de metade da produção barbosiana. De regresso a Portugal, publicaria ainda, em 1536, um poema intitulado Antimoria, no qual ataca o célebre Encomium moriae, de Erasmo, projeto a que dedicou seis anos. Deixando de parte esta última publicação, por se distanciar no tempo e no espaço das restantes, centremo-nos nos livros que vieram a lume em Salamanca num espaço temporal de seis anos. Os títulos completos, tal como constam nos originais, são os seguintes:

1. Arii Barbosae Lusitani in verba M. Fabii. Quid? quod E' reliqua. Relectio de Verbis Obliquis. [Cólofon:] Impressum Salmanticae Idibus Iuniis anno a genesi liberatoris nostri \& salutiferi Iesu. M.D.Xi

2. Arii Barbosae Lusitani Relectio, cui Titulus Epometria. [Cólofon:] Impressum Salmanticae, v. nonas Julij. M.D.Xv

3. ARATORIS CARDINALIS HISTORIA APOSTOLICA CVM/ Cõmentariis Arii Barbosae Lusitani. [Cólofon:] Impressum Salmanticae in aedibus Ioannis de Porris Mense Aprili. M.D.XVI.

4. Arii barbosae lusitani relectio: cui titulus prosodia; Arii Barbosae Lusitani relectio: cui titulus orthographia; Eiusdem Arii B. L. Nonnulla Epigrãmata. [Cólofon:] Impressum Salmanticae: Mense Decembri. Anno. M.D.XVII

Como se pode verificar, estas publicações, com exceção da terceira, não referem a tipografia, limitando-se a indicar o local: impressum Salmanticae. Esta lacuna tem uma explicação contextual, relativa à história da imprensa. Esta era uma realidade bastante recente em Espanha à data das edições barbosianas efetuadas em Salamanca, dado que a primeira oficina tipográfica surgiu apenas em 1474 em Valência. Só cinco anos depois é que a tipografia aparece em Salamanca, pela mão de António de Nebrija, que via na arte tipográfica um meio eficaz para expandir o seu saber e prestígio. Todavia, até as famosíssimas Introductiones Latinae (1481, 1482, 1485 e 1492) e a Gramatica Castellana (1492) omitem a identidade do tipógrafo. O anonimato dos primeiros tipógrafos salmantinos tem, segundo Cuesta Gutiérrez, a seguinte explicação: 
Sabiendo el concepto que como clase social tenía la artesanía, Nebrija, como catedrático de la Universidad, no podría estampar su nombre en este trabajo manual, incompatible con su cargo. ${ }^{2}$

De facto, só em 1496 aparece o nome do primeiro mestre tipógrafo num livro impresso em Salamanca, Leonardo Hutz, também conhecido como Leonardo, o Alemão. E é apenas em 1505 que se passam a conhecer nomes de tipógrafos espanhóis, pertencendo a Pedro de Pascua o lugar cimeiro, que naquela data deu à estampa o Quaderno de las leyes y nuevas decisiones sobre las dudas de derecho que solian y suelen ocurrir en estos Reynos ${ }^{3}$. $\mathrm{O}$ que verificamos, pois, confrontando estes dados com os que constam nas edições barbosianas, é que no primeiro quartel de Quinhentos há vários casos em que o tipógrafo ainda permanece no anonimato. Todavia, o $\mathrm{Co}_{0}$ mentário à "Historia apostolica" escapa a este fenómeno: terá o tipógrafo João de Porres querido associar o seu nome e o prestígio da sua casa a uma obra de inquestionável valor?

Se os opúsculos de Barbosa foram também impressos na tipografia de João de Porres, tal como o Comentário à "Historia apostolica", é algo que não podemos afirmar, mas admitimos como provável que tenha sido este o tipógrafo a imprimir todos os trabalhos atrás referidos, com exceção talvez do primeiro. Esta suspeição é reforçada por alguns factos. O Comentário à "Historia apostolica" é a consubstanciação das lições que o mestre português ministrou em 1513, conforme se pode ler no início do prefácio ao primeiro livro do Comentário (fl. ii), mas a verdade é que a obra só é publicada três anos mais tarde. Entretanto, vem a lume em 1515 a Epometria, um tratado sobre métrica latina que poderá ter sido uma resposta às dificuldades sentidas pelos seus discípulos na análise métrica dos hexâmetros dactílicos que compõem a Historia apostolica de Arátor. E apenas um ano depois da publicação do Comentário, Barbosa edita a sua última publicação em solo castelhano, que engloba o De Prosodia e o De Orthographia. Assim sendo, acreditamos que as publicações de 1515, 1516 e 1517 tenham sido impressas na mesma tipografia, explicitamente referenciada no cólofon do Comentário à "Historia apostolica": in aedibus Ioannis de Porris.

Além do local de edição, destacamos ainda o pormenor da datação das obras. O Comentário à "Historia apostolica" e o conjunto De Prosodial De Orthographia registam o ano e o mês: Mense Aprili. M.D.XVI e Mense Decembri. Anno. M.D.XVII, respetivamente. O De Verbis obliquis e a Epometria vão ao pormenor de apresentar o dia exato em que as obras foram editadas, 13

\footnotetext{
${ }^{2}$ Luisa Cuesta Gutiérrez, La imprenta en Salamanca: Avance al estudio de la tipografia salmantina (1480-1944), Salamanca, Ed. Universidad de Salamanca, 1960, p. 11.

${ }^{3}$ Ibidem, p. 14 e 24.
} 
de junho e 3 de julho, respetivamente, em datação romana (Idibus Iuniis e $v$. nonas Julij).

Passemos a outro nível de análise, focando em exclusivo o Comentário à "Historia apostolica". Apresentamos desde já alguns pormenores editoriais, reproduzindo parte do primeiro e do último fólio da obra supracitada: ARATORIS CARDINALISHISTORIAAPOSTOLICA CVM
CÓmentarilsAriiBarbof lufitani:

\section{Exprivilegfo ptitugform \\ Nequis in Hifinania uentid antex cudat fine atifitifiu permiffu ne. IHeophilus ad Lectoré de rioua Cómeritatlotic Arij Lufitani Praceptoris fui.}

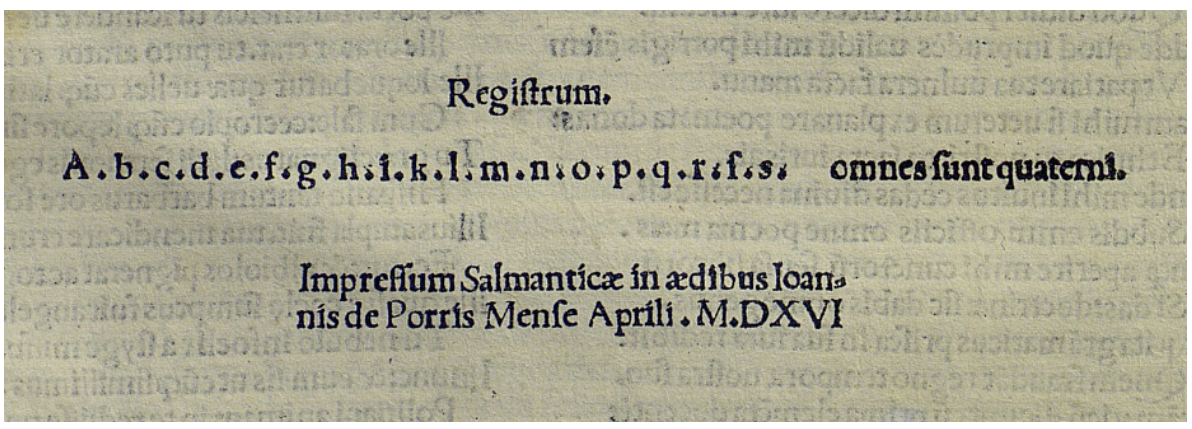

Tal como se pode ler na primeira imagem, o livro abre com um poema de Teófilo sobre este comentário. Trata-se de uma elegia de circunstância em onze dísticos elegíacos onde se glorifica a empresa barbosiana. No verso do primeiro fólio, Barbosa apresenta um interessante poema em quarenta e um dísticos elegíacos, onde louva Arátor e a sua Historia apostolica, rejeita os modelos dos heróis épicos clássicos (Aquiles e Ulisses), propondo como exemplares os heróis do poema aratoriano, Pedro e Paulo. Nos três fólios seguintes encontrase o prefácio ao primeiro livro de Arátor e uma brevíssima biobibliografia do poeta italiano, onde Barbosa segue de perto as informações de Aldo Manúcio que constam na primeira edição impressa da Historia apostolica, publicada em Veneza em 1502. Este facto é relevante, na medida em que Barbosa é sempre fiel à edição aldina, mesmo quando desconfia das opções do tipógrafo italiano, tal como acontece, por exemplo, na ordem por que transcreve os versos 19 e 20 da secção XV (fl. cxxxvii):

\section{Auctori certare fuo.defcendit ab aftrís (Aucta dies latuít.caligantefogtenebra) Lux oculos claufura meos: \& abígne corufco}


Como é evidente, os dois últimos versos estão trocados, pois a ordem correta é Descendit ab astris / lux oculos clausura meos e et ab igne corusco / aucta dies latuit. $\mathrm{Na}$ verdade, todas as outras edições que conhecemos registam os versos por esta ordem e o próprio Barbosa segue esta sequência na explicação que faz dos mesmos, mais adiante. No entanto, pensamos que o humanista aveirense se terá apercebido desta incongruência da edição de Aldo Manúcio ao colocar o verso aucta dies [...] tenebrae (v. 20) entre parênteses.

Depois do prefácio ao primeiro livro da Historia apostolica e dos prolegómenos à vida e obra de Arátor, da lavra de Barbosa, começa o texto propriamente dito, realizando o humanista a transcrição e comentário da obra aratoriana. A prefaciar a própria Historia apostolica, Arátor incluiu as cartas a Floriano e ao papa Vigílio, respetivamente o corretor e o destinatário da obra, que Barbosa transcreve e comenta dos fólios iiii a xi. Segue-se depois, até ao fólio cii, a transcrição das vinte e cinco secções da primeira parte do poema épico, e o minucioso comentário do humanista acerca desses mil e setenta e seis versos, que constituem a gesta de S. Pedro, tendo Arátor parafraseado os Atos dos apóstolos até ao capítulo doze. O comentário ao segundo livro segue uma estrutura muito similar à do primeiro. Encontramos também um prefácio, muito semelhante ao do primeiro livro, no tom, no estilo e até nas ideias, que ocupa três fólios (cii-ciiii) e termina com um poema de oitenta e oito hexâmetros dactílicos (fólios ciiii e ciiii $\mathrm{v}^{\mathrm{o}}$ ), onde Barbosa dedica a sua obra a Deus e à Virgem. Segue-se a transcrição das dezanove secções do segundo livro da Historia apostolica, num total de mil duzentos e cinquenta versos e respetivo comentário (fólios ciiii $\mathrm{v}^{\mathrm{o}} \mathrm{a} \mathrm{cl}$ ).

No que diz respeito apenas à parte do comentário ao segundo livro, devemos salientar que Barbosa dedica o dobro dos fólios ao estudo do primeiro livro, ainda que este registe menor número de versos. Na verdade, os mil duzentos e cinquenta versos versos do segundo livro da Historia apostolica são comentados em quarenta e seis fólios, ao passo que os mil e setenta e seis versos do primeiro lhe merecem nada menos que noventa e quatro fólios. A obra finaliza com uma errata e um conjunto de cinco epigramas, onde Barbosa defende o mérito do Comentário e ataca aqueles que contra ele se vão insurgindo.

Do ponto de vista editorial, pensamos ter bastante interesse a errata suprareferida, que ocupa aproximadamente duas páginas (a quase totalidade do fólio cl e o início do cli). Numa primeira nota, salientamos que o comentador dedica noventa e uma linhas ao primeiro livro e apenas quatro ao segundo. O humanista apresenta uma lista de algumas correções a introduzir no texto (corrige), como se pode verificar no excerto: 


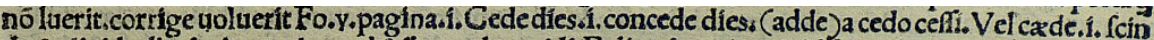

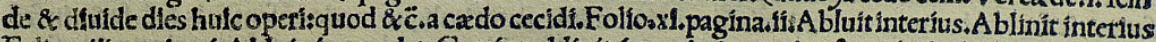

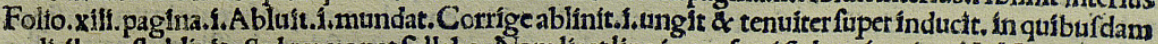
codicibus eft abliuit. Sed repugnat fyllaba. Nam licet lino in prefenti fit breuis prifor。 Vt Ver. thefaus rís relínes:tamen in praterito é lóga.líui. Hor.conditum liui.tuel leui. Eft ergolegendum A blinit:quía

No entanto, mais do que emendar, Aires Barbosa tem sobretudo a preocupação de adicionar novas informações aos comentários já produzidos. Veja-se, a título exemplificativo, a addenda que apresentamos de seguida, onde o humanista entende acrescentar às observações já feitas no fólio iiii o testemunho de mais cinco autores, dois cristãos, Agostinho e Hilário, e três clássicos, Plínio, Tito Lívio e Juvenal:

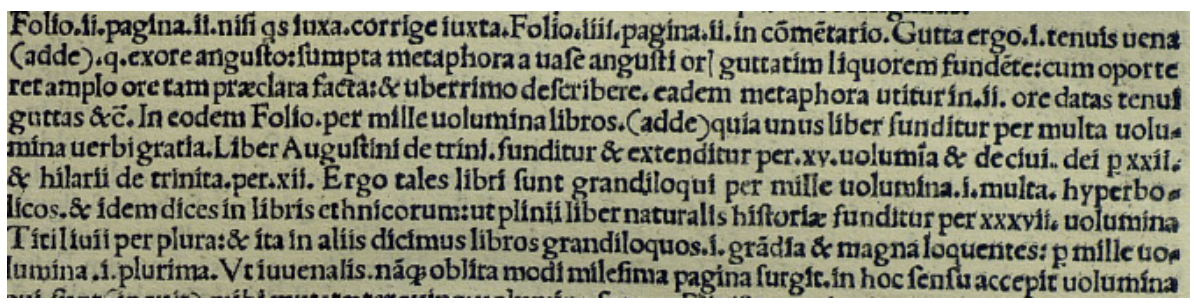

Antes deste trabalho "de última hora", chamemos-lhe assim, Aires Barbosa empreendeu uma profunda revisão ao Comentário, durante três anos, tal como o próprio revela logo na abertura do prefácio ao primeiro livro, esclarecendo que não o publicou mais cedo por se demorar na revisão e aperfeiçoamento do texto:

Petitis cotidie a me, auditores amantissimi, uel potius precibus omnibus oratis et obtestamini ut edam commentarios, quos ipse tumultuaria opera composui, nec per occupationes ex illo tempore uidere licuit, cum Aratorem poetam, qui acta apostolorum metrice scripsit, ab hinc triennium publice interpretabar.

Todos os dias me pedis, caríssimos ouvintes, ou antes, implorais com todas as preces e suplicais que publique os comentários que eu mesmo compus numa obra desorganizada e que, durante as minhas ocupações, nesse tempo, não me foi possível rever, quando eu comentava publicamente, há um triénio, o poeta Arátor, que escreveu em verso os Atos dos apóstolos. ${ }^{4}$

Aliás, o menor fôlego de Barbosa no De Prosodia é explicado nas páginas iniciais deste opúsculo pelo aturado labor dedicado à revisão das provas tipográficas do Comentário à "Historia apostolica", cuja correção lhe consumiu o tempo e as forças. É que, diz Barbosa, os erros pululavam não como serpentes, mas

\footnotetext{
${ }^{4}$ Aires Barbosa, Aratoris cardinalis Historia apostolica cum commentariis, fl. ii, tradução e sublinhado nossos.
} 
como se fossem sementes de papoilas:

Cupiebam ego in uestram et publicam omnium utilitatem commentarios in Aratorem meos formis istis uulgatis propagare [...]. Coepi etiam quosdam uitio excussorum pullulantes errores non tanquam excetrae, sed quasi papauerum capita stilo resecare. ${ }^{5}$

Assim, no final da Errata ao Comentário, e em jeito de conclusão, o humanista faz uma breve reflexão acerca do aperfeiçoamento do seu trabalho. Usando uma linguagem alegórica, Barbosa afirma que, tal como na ceifa caem sempre algumas espigas dos molhos cortados e na vindima se perdem irremediavelmente alguns bagos de uva, assim ele próprio, Aires Barbosa, qual ceifeiro ou vindimador, admite que algum erro lhe possa ter escapado nesse trabalho de revisão atenta da própria obra:

Haec, auditores suauissimi, in transitu lectionis tumultuariae emaculauimus. Sed adhuc (ut arbitror) multa oculos nostros omnium infirmissimos fugerunt. Vt enim [...] nullus est agricola tam gnauus cui non aliquid spicarum ex demessis manipulis in terram defluat, uel qui non aliquid praetereat quod post terga metentium pauperes, ut Ruth illa Moabitis, legere possint, [...] utque cautus uinitor [...] semper aliquid relinquit, quod post uindemiam ad incustoditas pueri uineas decurrentes sublegant, ita nullus est in libraria impressione tam callidus errorum undique pullulantium aut demessor aut uindemiator quin aliquid praetereat uel addendum, uel tollendum, uel mutandum, uel denique interpungendum dispungendumue.

No final desta lição tumultuária, dulcíssimos ouvintes, purificámos estes passos. Mas ainda, segundo julgo, muitos outros escaparam aos nossos olhos tão débeis de tudo. Tal como não há agricultor tão diligente a quem não caiam por terra algumas espigas dos molhos cortados, ou que não deixe algo que, atrás dos segadores, os pobres, como Rute, a famosa moabita $[R u t h 2,3]$, não possam recolher, e tal como o cauteloso vindimador deixa sempre alguma coisa que, depois da vindima, os meninos, precipitando-se para as vinhas sem guarda, vêm roubar, assim não existe também, na impressão de livros, nenhum ceifeiro ou vindimador tão conhecedor dos erros que pululam por todo o lado que não lhe escape algo para acrescentar, ou para suprimir, ou para mudar, ou, finalmente, para pontuar ou tirar pontuação. ${ }^{6}$

Esta reflexão, para além de literariamente valorizada por belas metáforas de sabor bíblico, revela ainda o preceito horaciano de que é necessário deixar amadurecer a obra para que ela possa ser apresentada no máximo esplendor.

\footnotetext{
${ }^{5}$ Aires Barbosa, De Prosodia, fl. ii.

${ }^{6}$ Aires Barbosa, Aratoris cardinalis Historia apostolica cum commentariis, $\mathrm{fl}$. cl vo e cli, tradução nossa.
} 
De facto, é esse o motivo que o humanista apresenta aos discípulos para só em 1516, passados três anos, atender às preces destes e publicar finalmente o Comentário:

Vua incocta peracerba est, deinde maturata dulcescit; ita sane longo tempore opus est, et, ut Horatius praecipit, nouennio, si uolumus ingenii nostri fructus [...] coctos esse.

A uva verde é muito azeda, mas depois de amadurecer torna-se doce; do mesmo modo, é realmente necessário um longo tempo, nove anos como recomenda Horácio [Arte Poética, vv. 388-389], se queremos que os frutos do nosso talento estejam maduros. ${ }^{7}$

Esta minuciosa revisão do texto subentende também a esperança de Aires Barbosa de que o Comentário granjearia sucesso editorial, o que não viria a acontecer. No entanto, alguns entraves parecem ter existido, pois o humanista, em diversos pontos, dissemina defesas enérgicas face aos críticos, que, entre outras coisas, o acusam de "meter foice em seara alheia”. É que, não sendo teólogo, Barbosa comenta e analisa detalhadamente a epopeia bíblica de Arátor, um enorme atrevimento na perspetiva dominante de uma universidade extremamente conservadora como era a de Salamanca. Essa defesa converte-se não raras vezes em insulto: cães de Cila e malfazeja raça de piratas $^{8}$, assim chama Barbosa aos seus detratores. No entender do humanista, as acusações dos críticos (ainda que eventuais ou apenas previsíveis) são injustificadas pela dedicação e saber que Barbosa colocou quer na produção, quer na revisão do texto, e por isso o humanista tem o seguinte desabafo:

Hoc factum meum fortassis haud reprehendendum uos oppido quam maligne inuertitis, et quia "mala sunt uicina bonis", quod rectum est intorquetis... Nam simplicem cultum uos appellatis fucum, et concessa ornamenta uocatis meretricum lenocinia.

Vós perverteis de forma completamente maldosa este meu trabalho, porventura irrepreensível, e, porque "as coisas boas são vizinhas das más"[Ov., Rem. Am., 323], retorceis o que é reto... Realmente, o culto singelo, vós o apelidais de disfarce, e aos ornamentos permitidos chamais adornos de meretrizes. ${ }^{9}$

Nem a dimensão da obra escapa ao humanista, que antecipa a acusação. No epigrama que encerra o Comentário à "Historia apostolica", Barbosa responde satiricamente a alguém que o acusava de a obra ser demasiado extensa: se

\footnotetext{
${ }^{7}$ Ibidem, fl. iiii, tradução nossa.

${ }^{8}$ Ibidem, fl. cii vo: Scyllaei canes et maleficum genum piratarum. Tradução nossa.

${ }^{9}$ Ibidem, fl. ciii, tradução nossa.
} 
eram muitos os comentários, lesse poucos, tornando, desta forma, a obra mais $\operatorname{curta}^{10}$. Com efeito, a discrepância entre os sonhos editoriais de Barbosa e a efetiva receção do Comentário revela que o mercado livreiro do primeiro quartel do século XVI poderia revelar frutos amargos para os autores da época. Transcrevemos um excerto de um epigrama onde o humanista aveirense se dirige à Academia salmanticense para ilustrar o quão grande deve ter sido a frustração de Aires Barbosa, tendo em conta o entusiasmo patente neste texto:

Cetera quae aedificas pereunt; uisetur in omni / gente, uel in populo uel regione meum.

Tudo o resto que edificas é perecível; a minha obra será contemplada / por todo o país, por todo o povo, por toda a região.... ${ }^{11}$

Voltando às questões gráficas, o caráter incipiente da imprensa salmantina no dealbar do século XVI e o preço do papel podem explicar algumas deficiências estéticas do Comentário. Comecemos pela compactação do texto. Para ilustrar este aspeto, apresentamos um fólio inteiro, o cxxxi:

${ }^{10}$ Ibidem, fl. cli vo: Ille putans mea commentaria longa, / pauca legat! Nostrum sic breuiabit opus.

${ }^{11} \mathrm{Ibidem}$, fl. cli, tradução nossa. Os versos transcritos são o 25 e o 26 do penúltimo dos cinco epigramas com que termina a obra e tem por título Academiam Salmanticensem alloquitur idem Arius B[arbosa] L[usitanus]. 


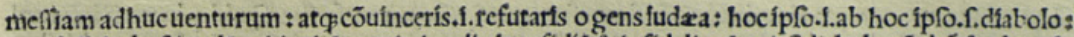

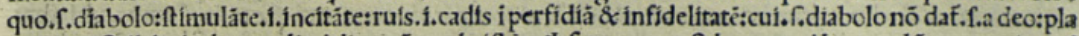
cere ore.f.tibl o ludax ut aligd dicat cōtra chriftü:qd.f. os mouet.f.damonad loquendü:terrore.i.teır

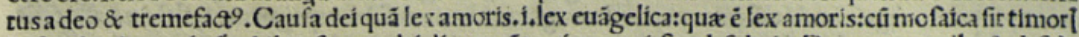
\& feruítutis:comítat: phibet.f. metu dei dicere côtrariasuoto.j.fuo defiderio. Dxmon.n.uellet \& defide

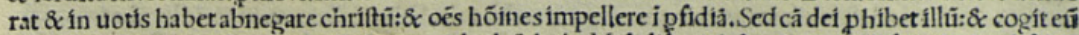

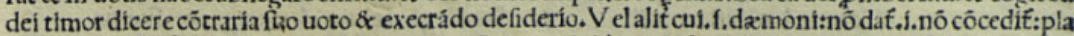

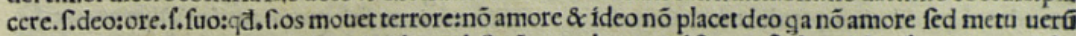

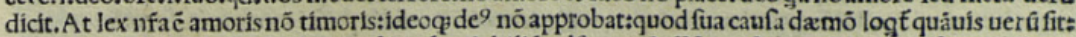
ga tremefact 9 illud pfert nô beniuolétix laudabili i pulfu mot ${ }^{9}$. (Hace cft)uera fides:quà.fuerã effenfí hoftes farētur. Túc.f.dæmonerepelléte a fe iudros illos:qua fpectacula.i.quos ludos plebi.f.ephefios

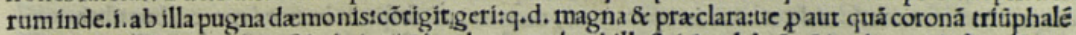

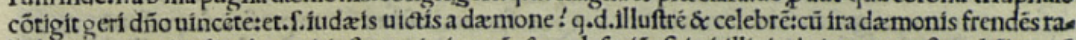
bido murmure:ira ditco bene.i.iufte noxia.í.nocés \& malefaciēs fuís.i.illis iudatis quos ut fuos hêbat:rú

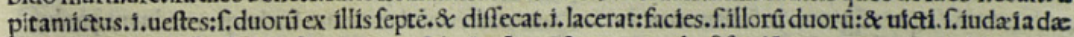
mone:fugitüt pícula.f.diaboli in eos irruétis: \& cóuertuit terga nuda. f. fugiêtes:patore pracipitil. 1. metu praxcipitáte. Dixit auitterga nuda:infpiciés habitūantiquoru militû:g terga nuda hẻbāt:pectora hoftiop pofita dútuxat armistegêtes. Vnde Saluftianus Catilina. Naminquit in fuga fpare falutê:cum arma qui

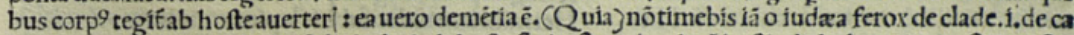
lamicare:quæ fic perís hofte.f:diabolo.1.ab hofte focio.f.tuo $: q$. d.cü hoftis diabolus cótra te furgat fos cíü tuû:nihîl eft quod tibinō fit tímendū. Cui.fíiudex idè diaboluséautor.i.impulfơr criminis.i.infide litatis: \& punitor.i.carnifex \&itortor:ne fit pulfus.f.dazmon acorpore damoniaci: te fudíce.1.te o itudaa

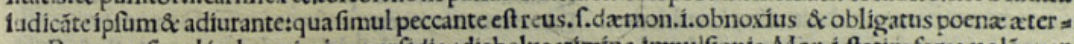
nx.Peccat.n.fimul fudxa crimine perfidia:diaboluscrimíne impulfionis.Mox.i.ftatim fama uolâs per urbem.f.cplsefiorum ubíg: fparfit.i.diuulgauir.f.hoc: \&cedere.j.edebat hoc eft uulgabat. f.famatut nos

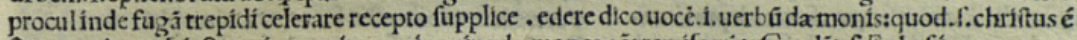
fumma uirtus déf. Copatris:cum In nomińne eius dxmones côtremifcerét: Gaudét.f. Ep phefií concurrere f. ad paulum:intrare in latices pios. f. baptifmi: \& lauare maculas uetuftas.f.peccatorifonte nouo.f.bas

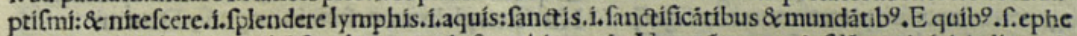
fiis baptizatis datur onnib 9 fimuluna xtas infons. i.innocés. Nam oés erant elufdéæatatis fpiritalis:quá uis atate corporea unus effet fenex:alter fuuenis:itaqzalius alio uel feniorucl iunior. (Aft alii.) multein= quir lucas ex ès qui fuerát curiofa fectati contulerût libros \& $<$ combufferât eos corã omnib 9 : $\&$ conputa tis precifs illorûinuenerút pecunía denarforum quinquaginta millium. (Aftalii.) f.necromantici $\alpha g e$ ne:hilaci:ponút fncendir.i.cremant: $\alpha$ ignemapponunt:librismagicis:ut mereantur aquas.f. baptifmi: \&́ uitantignes.f.gehénæ:ígnibus.1.comburédolibros magicos. Flăma.f.qua libri funt côbufti nimis ats dua fíalta \& pia fuit:cuius fulgor euolat fuper athera.i.coelum grata deo \& iuctida făma:\& fauill $x$. í cíneres librorü combuftorum tales periere.i. petieruit \& intraucrunt coclum:quia ad tribunal fummi def peruenerunt. Pofuere etiam precium libellis.f. combuftis :quinquaginta millita númo:um.f.denariorû: uel quía tanto preclo efient empti quốdam:uel quia fi uenditi fuifient táto precio.i.L.millibus denario rum uendi potuiffent quonian nocentes.í.malefici $\&$ necromáticímeruere abolere.i.purgare nefas.í. peccatum fuú:fic.f.numero quínquagenarioremiflionè denotante. Caufa huius figuræ efl hac. f. qua fequitur. Nam quínquagenarius numerustefertur ad poenitentiâ \& peccatorưremiffî̀né:unde $\delta \&$ quín quagefimus eft poeniteétix pfalınus qui incipif́: Miferere meldeus fecundü magnă nif́erícordiam triam. \& ce. \& quinquagefimus eft remiffionis annus:qui iubilaus appellatur:dietus a fobel .i.buccina ut ait Rab.Salo. Nam in leuitico pracepirdominus clangere tobel.1. buccina menfe feptimo: \& decima die menfis propiciationis tempus effe in uniuerfa terra l/raelitica. Hinc iubilaxus eft diaus hicannus quin̄̄gefimus :quodebitx relaxabátur pecunix. exules reuocabătur: feruidonabanturlibertate : ur tellusim munis eo anno haberetur ac quafeüg; fua fponte fruges tuliffectribulibus effent $\&$ hof pitibus commins nes. qua uilius ueniflent antiquis poffeffioribus redhibebätur. Nam quáto annus lubilaíułcinior infla bat tunto minoris bona aftimabätur:ac uiceinuerfa tả to maioris quâto longíus diftabat jubilaxus. ( $\mathrm{Nu}$

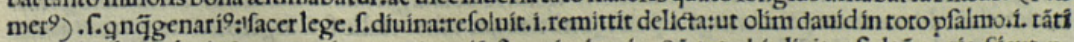
numeri:diluit.i. lauit \& purgauit p poenitentiá:fua crimina.i. petã.toto hic liceter fed tí pprie. Sicut.n。 a quot dicímus quotus:quod refeı tur ad quátitatem diícretamsita a tot dicimus tớus quod ad eádé quá tițtem reducif́. Sed quot ${ }^{\circ}$ eft in ufü:totus nó eft in ufu hac lignificatióe fed alia multứ diucrfa. Vtimur

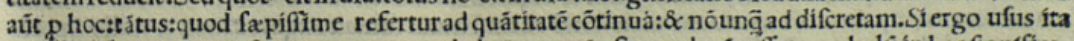
emolliuiffet totus a tot:ficut quotus a quot deductumrecte fonat:elegás effet uocabulti in hac fignificas tione. Caeterú defideram ${ }^{9}$ hic quáticatem $\delta$ menfumfyllabx. Videt.n. repugnare fi tot 9 a tot joducat: 
Esta mancha gráfica é a mais comum ao longo da obra: trata-se de um texto compacto, saturado de abreviaturas, que regista cinquenta e sete linhas por cada fólio. Encontramos, todavia, também com alguma frequência, aquela que é praticamente a única variante em termos de mancha gráfica:

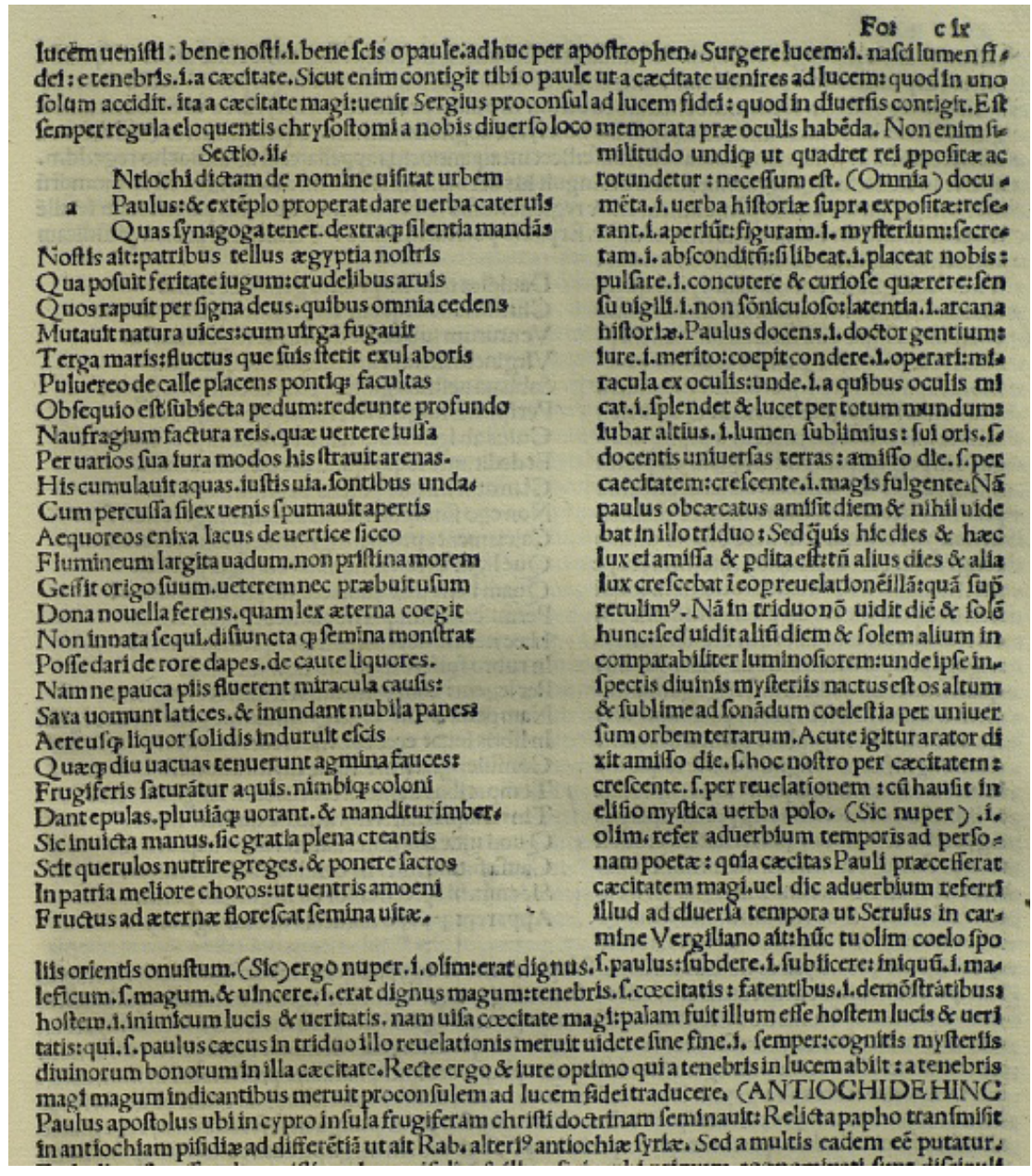

Existe um fólio semelhante a este sempre que Barbosa muda de secção, transcrevendo um novo conjunto de versos da Historia apostolica aratoriana, ordinariamente encostados à margem esquerda. A imagem deixa transparecer o cuidado no aproveitamento de toda a página: é transcrita uma secção do poema, mas todo o espaço em seu redor é preenchido com comentários. Sabemos que o humanista passa de secção não porque haja qualquer corte ou espaçamento no texto, mas por transcrever em maiúsculas a primeira palavra ou expressão da secção seguinte. Neste caso concreto, a análise da segunda 
secção começa na antepenúltima linha da imagem em ANTIOCHI DEHINC. A maiusculação da segunda palavra destina-se a vincar melhor a passagem da primeira para a segunda secção, dado que Dehinc pertence ao comentário barbosiano e não ao poema de Arátor. Este procedimento é uma espécie de marcação de novo capítulo na obra.

Por outro lado, o Comentário revela uma quase total ausência de capitais ornamentadas. Era suposto o ilustrador desenhar a primeira letra no início de cada secção do poema, mas, das quarenta e oito capitais previstas, falta ilustrar quarenta e cinco, uma vez que o espaço em branco lhes está devidamente reservado. Reproduzimos uma das três capitais ornamentadas, referente ao início da primeira secção do segundo livro:

(SPIRITVSACCENSAM.) Haetenus Arator petri Barionæ prazdicationé:miracu la:carceré:cateraqg narrauit:qux ad ípfum princípéapoftolorí attínebăt. Nuncín hoc fectido libropaulitexítur hiftoria:\& clágor doctrină euangelícă fonans ubíq: nullisq̧3 nõterris, \& $x$ infulis exauditus defcribitur.In calce tero oper] corona utriuf̧̧ exponitur : qū ad martyríi gloríáamboRomam perue
ARATORIS SVBDIACONI ROMANAE EC fix cardinalis apoftolicx hiftorix; Liber fecundus. Secto prima.

ल Sub modío lucere uetāstfecernite faulum Dixitin oris opus. qué mox facrauitetité Omia pofie dedit.Cyprum falamina quelínquens Pergie adire paphum: qua ferturamoribusolim

Cuesta Gutiérrez, tendo uma perspetiva mais global das obras editadas na tipografia a que Barbosa recorreu, afirma: "Las obras de Porres llevan abundancia de curiosos grabados y letras floreadas"12. Ora, imagens não aparecem nem era previsto aparecerem no comentário barbosiano, mas as "letras floreadas" confirmam-se, faltando saber a razão de o ilustrador ter trabalhado tão pouco, pois apenas ornamentou uma capital no primeiro livro (fl. iii vo ) e duas no segundo livro (fl. cii e ciiii vo). Os restantes casos podem ser exemplificados pela imagem que se segue, correspondente ao início da terceira secção do segundo livro (fl. cxi):

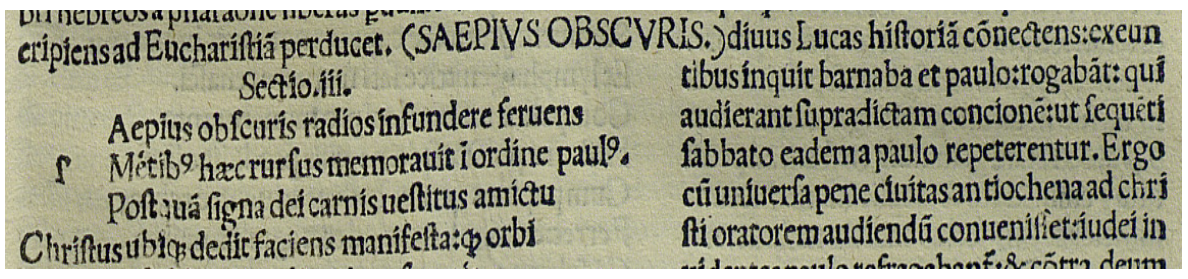

Como se pode observar, está reservado o espaço para a ilustração da primeira letra do primeiro verso do poema - neste caso o $S$ de Saepius -, mas a ilustração não está feita. $\mathrm{Na}$ imagem supra, é visível a passagem da segunda para a terceira secção no ponto em que o comentador transcreve em

${ }^{12}$ Luisa Cuesta Gutiérrez, op. cit., p. 24. 
maiúsculas o início do verso da secção seguinte: SAEPIVS OBSCVRIS. E se, neste caso, há uma razão objetiva para o uso de maiúsculas, a verdade é que no conjunto do Comentário se nota alguma arbitrariedade na sua utilização. Por exemplo, surgem esporadicamente maiúsculas sem qualquer razão justificativa no meio das frases e, quanto aos antropónimos e topónimos, estes aparecem arbitrariamente grafados tanto com maiúscula inicial como com minúscula. Ilustre-se este último caso a partir do fólio lxxxviii vo: Aeneam, Lucam, Arator, Perseus, mas plinio, palestinae, strabo, ouidio, india, entre outros. A este nível e ainda no mesmo fólio, a grafia do nome pomponius Mela é reveladora da flutuação de critérios. Resta a dúvida: a quem imputar tal arbitrariedade de critérios? Ao autor ou ao tipógrafo? A análise global do texto deixou-nos concluir, todavia, da existência de três casos em que a maiúscula é regularmente usada: o início de frase, o início de verso (os de Arátor) e o início de secção.

A pontuação levanta problemas semelhantes, que naturalmente se refletem na compactação do texto original, já que este apresenta apenas quatro sinais: o ponto final, o ponto de interrogação, os parênteses e os dois pontos, correspondendo este último com grande frequência à vírgula. Ademais, a dificuldade na leitura do texto é acrescida pela ausência de parágrafos ao longo da obra. E se, na transcrição do poema de Arátor, os versos aparecem em linhas separadas, já quando Barbosa cita conjuntos de versos no corpo do Comentário não há qualquer separação. Exemplos disso são os catorze hexâmetros datílicos da sua própria autoria que Barbosa cita no fólio cxxxviii em seis linhas, ou dez versos da Farsália, de Lucano, que ocupam apenas quatro linhas no fólio cxxxii.

Mas um dos fatores que mais contribui para a compactação do texto barbosiano é, sem dúvida, a grande frequência de abreviaturas. Por vezes, o seu desdobramento é dificultado por dois fatores. Primeiro, Barbosa usa abreviaturas que não se encontram em qualquer dicionário, a exemplo de .n.p. (fl. cxxxiii vo 1.30$)$, nomen proprium; e outras que, embora possamos admitir o seu eventual registo, não são habituais, como hõ, homo (fl. cxxi vo 1.5$)$, e cãm, causam (fl. cxxiii $\left.\mathrm{v}^{0}, 1.50\right)$. Em segundo lugar, nem sempre a mesma abreviatura deve ser desdobrada da mesma maneira, casos, por exemplo, de .q., passível de corresponder a quondam ou a quasi, e de tũ, desdobrável por tunc, mas também por tum. A questão das abreviaturas pode ser ilustrada a partir das cinco linhas retiradas do fólio cxxxii $\mathrm{v}^{\mathrm{o}}$, que reproduzimos abaixo e de que fazemos transcrição:

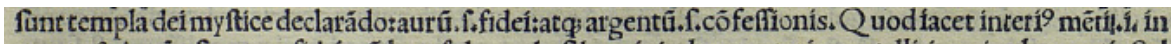
mente $\&$ in aia.f.aurum fideí:nô latet fub corde.Chomínis dura materies metalli:íauri uel argentí: fed aptius. 1.apte $\&$ clare:exagitat.i.mouet.f.mofes fub nốie auríillud.f.fidei aurú:quod chrift 9 amat. Mẹs obtulitaurú.f.ín templo dei:cuí fuerit fides preciofa.i.aurea \& magníprecil.Quinuiliusargentú ẻ auro:

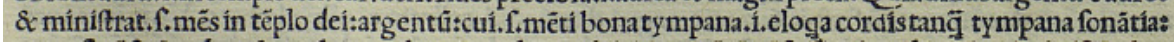


sunt templa Dei, mystice declarando; aurum, scilicet, fidei; atque argentum, scilicet, confessionis. Quod iacet interius menti, id est, in mente et in anima, scilicet, aurum fidei; non latet sub corde, scilicet, hominis; dura materies metalli, id est, auri uel argenti; sed apertius, id est, aperte et clare; exagitat, id est, mouet, scilicet, Moses sub nomine auri; illud, scilicet, fidei aurum, quod Christus amat. Mens obtulit aurum, scilicet, in templo Dei; cui fuerit fides pretiosa, id est, aurea et magni pretii, quia uilius argentum est auro; et ministrat, scilicet, mens in templo Dei; argentum cui, scilicet, menti; bona tympana, id est, eloquia, cordis, tanquam tympana sonantia

Existem abreviaturas correntes, como o til, que corresponde à nasal $m$ ou $n$ (declarãdo, mẽti, aĩa, nõ); o sinal ${ }^{9}$, que abrevia a terminação "us" (inter $\left.i^{9}\right)$; ou a enclítica que, abreviada por $q_{3}\left(a t q_{3}\right)$. Contudo, as abreviaturas mais frequentes são .i. e .s., correspondentes a id est e scilicet, que podemos traduzir por isto $e ́$, quer dizer. A repetição exaustiva destas duas expressões, que introduzem a explicação da ordem ou do significado de um vocábulo ou expressão, confere alguma monotonia ao Comentário, mas confirma o interesse didático desta obra, destinada fundamentalmente aos discípulos, tal como Barbosa afirma repetidamente nos prefácios aos dois livros. Na verdade, embora notemos neste caso alguma falta de erudição, o comentário barbosiano fornece-nos, por outro lado, um magnífico testemunho do ensino do latim e da literatura latina nos inícios de Quinhentos.

Deixámos para o fim uma questão fundamental, sobretudo se atendermos ao epíteto do nosso autor: como aparece o grego no Comentário? Nesta, como em todas as outras obras de Aires Barbosa publicadas em Salamanca, a língua de Homero é sempre transcrita em caracteres latinos. Ora, isso pode parecer estranho, tendo em conta a mestria reputada a Aires Barbosa nesse âmbito e a grande frequência com que aparecem expressões, frases e citações em grego: autores como Luciano, Aristófanes, Píndaro e Homero, por exemplo, são quase sempre citados em grego. Mas o facto explica-se pelas contingências técnicas da tipografia salmantina da época, que não tinha caracteres gregos. É certo que, frequentemente, as citações em grego são de menor dimensão, em geral pequenas frases ou títulos de obras, mas esporadicamente deparamo-nos com textos de alguma dimensão, como no fólio cxlii, onde Barbosa transcreve um passo de Demóstenes (apresentamos também a transcrição do texto em caracteres gregos):

\section{aabua0. Lategubiactior tepeitasincumbitutuerbis utar Demolthenís utís naucleron pantepífotería praxanta cai pafi catefcetuafanta toploion aphon hypelambane fothefeftai:eita cheimonichrifamenon cal ponefanton auto tonfceuson icai fyntribenton holos:tesnauagias aicioto. Neć.n. fempars fíné cóti}

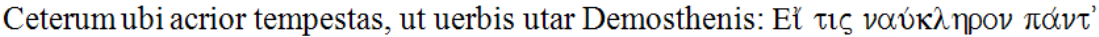

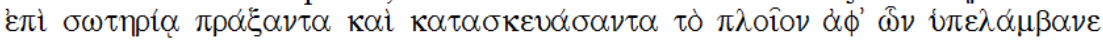

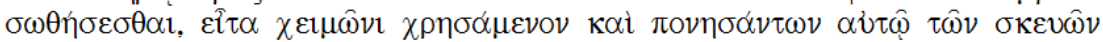

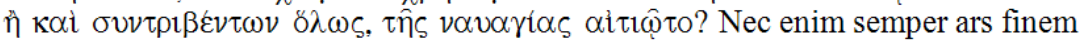


A transcrição do grego em caracteres latinos, que constitui uma enorme dificuldade para quem lê e transcreve o original, pode, no entanto, ter algum interesse para o estudo da pronúncia da língua helénica no início do século XVI. Apresentamos dois exemplos referentes à pregação de S. Paulo em Atenas, comentada no segundo livro. No primeiro caso, o humanista refere uma entrada da Suda (no 1272), que explica a origem do gentílico "Cecrópidas" para designar os Atenienses (fl. cxxiiii); no segundo, Barbosa cita um passo de Luciano (Herm., 64), onde diz que os juízes julgavam no Areópago de noite para que se atendesse àquilo que era dito e não a quem o dizia (fl. cxxiii vo):

onto genos ocefe tas athenas: hothen cecroüidæ oiatheginltaurauit. Vñ \& fúdás cecrops aigyptios Cecropíd $x$ ficut a romulas: hothen cecropid $x$ oi athenaíol. Dictitur ergo atheniefes a cecrope rege

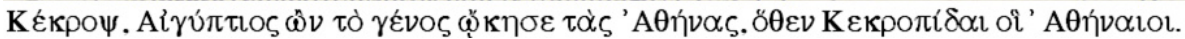

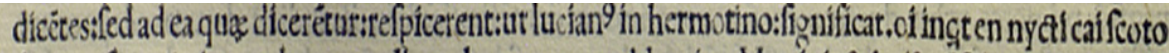
dicazoyfinaosmiestus legontasalles ta legomena apsblepoien. Meninit \& hui? côfuetudinis macros

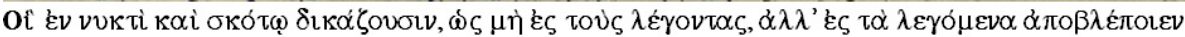

O cotejo que aqui estabelecemos permite-nos tirar algumas conclusões a respeito da pronúncia do grego ao tempo do humanista: a vogal inicial ou ditongo com espírito áspero não era aspirada $(o i$, os) nos monossílabos, mas era-o em palavras com mais do que uma sílaba (hothen); o thêta era sempre aspirado (athenas); o êta correspondia ao som /e/ (ocese), mas em sílaba final liase /i/ (mi). Na transcrição latina é-nos impossível verificar a distinção, ao nível da prosódia, entre épsilon e êta ou entre ómicron e ómega, dado que a grafia é sempre igual ( $\underline{e}$ e $\underline{o}$, respetivamente), mas cremos que ela era feita.

Em suma, os originais salmantinos da obra barbosiana apresentam desafios a qualquer latinista, mas podem lançar pistas para quem se aventura na edição crítica de outros autores da mesma época. A leitura não é de todo isenta de dificuldades e cremos ser esse um dos motivos pelo qual uma obra tão importante como a do humanista aveirense só agora, no século XXI, começa a ser reeditada. Por outro lado, as edições barbosianas são de grande relevo para a história da imprensa em geral, e particularmente para a história da imprensa em Salamanca. 